\title{
The effect of CCC on growth and gibberellin content of tomato plants ${ }^{1}$
}

\author{
J. van Bragt \\ Department of Horticulture, Agricultural University, Wageningen, the Netherlands
}

Received 17 March 1969

\section{Summary}

A single application of (2-chloroethyl)trimethylammonium chloride (CCC) to the roots of young tomato plants $\mathrm{cv}$. 'Moneymaker' reduced the growth rate of these plants for about three weeks. From this time the growth rate of treated plants was higher compared with the controls, which was the result of accelerated growth of the internodes at the top of the treated plants. Plant material from above the cotyledons was extracted on day 5 from CCC treatment and material from the top of the plants on day 29.

The extracts were assayed for gibberellin-like substances. It was found that the extracts from CCC-treated plants, obtained on day 5 and day 29 from treatment, contained slightly more gibberellin-like substances compared with control plants. These findings suggest that $\mathrm{CCC}$ does not inhibit gibberellin synthesis in tomato plants.

\section{Introduction}

An earlier study (Klapwijk, 1966) demonstrated that a single application of (2-chloroethyl)trimethylammonium chloride (CCC) to the roots of tomato plants reduced growth for about three weeks. From this time increased growth was observed. The growth retardant $\mathrm{CCC}$ is considered an inhibitor of gibberellin synthesis in plants (Zeevaart, 1966). The purpose of the present study is to examine the effect of CCC treatment on gibberellin-like substances in extracts from shoots at the stage of CCCinhibited growth, and also from shoots which, later on, were at the stage of increased growth.

\section{Plant material}

Seedlings of Lycopersicon esculentum Mill. 'Moneymaker' were grown in plastic pots of $680 \mathrm{ml}$, filled with fertile soil, in a greenhouse at prevailing light. Night temperatures above $18^{\circ} \mathrm{C}$ with day temperatures above $21^{\circ} \mathrm{C}$ were maintained. When the first true leaf was $4 \mathrm{~cm}$ long, the plants were selected on uniformity and divided into two groups. The plants of one group were treated with $25 \mathrm{ml}$ of an aqueous

1 Publication 323, Laboratorium voor Tuinbouwplantenteelt, Landbouwhogeschool, Wageningen, the Netherlands. 
solution containing $100 \mathrm{mg}$ of $\mathrm{CCC}$ applied to the soil. On the same occasion the plants of the other (control) group received $25 \mathrm{ml}$ of water. On day 5 from the time of treatment the first harvest was made. A number of treated and control plants were decapitated just above the cotyledonary node and the upper parts immediately stored at $-26^{\circ} \mathrm{C}$, until use. From this time the growth of 20 treated and 20 control plants was recorded twice a week using the data from measurements of internode lengths. The second harvest was made when the growth rate of the treated plants was greater when compared with the control plants. At this time the upper parts of the plants, including three internodes longer than $0.3 \mathrm{~cm}$, were harvested and immediately stored at $-26^{\circ} \mathrm{C}$, until use.

Five replicates were carried out during April-August 1968, with similar results. In the following one experiment is given as an example.

\section{Gibberellin-like substances in plant extracts}

\section{Plant extraction}

The frozen plant material was homogenized with methanol in a Waring blendor and stored at $3{ }^{\circ} \mathrm{C}$ for 24 hours. The mixture was filtered and two subsequent extractions were made with $80 \%$ methanol at $21^{\circ} \mathrm{C}$ during 24 and 6 hours respectively. The combined extracts were evaporated to dryness at temperatures not exceeding $30^{\circ} \mathrm{C}$, under reduced pressure. The residue was dissolved in a mixture of equal volumes of $0.1 \mathrm{M}$ phosphate buffer $\mathrm{pH} 8.2$ (Zeevaart, 1966) and petroleum ether (boiling range $40-60^{\circ} \mathrm{C}$ ). The buffer phase was partitioned three times against petroleum ether. This petroleum ether was discarded and the aqueous phase adjusted to $\mathrm{pH} 2.3$ with $\mathrm{H}_{2} \mathrm{SO}_{4}$ and subsequently extracted four times with ethyl acetate. The aqueous phase was discarded and the combined ethyl acetate extracts freed from water by freezing and subsequent separation by filtration of ice and ethyl acetate. The ethyl acetate was evaporated to dryness under reduced pressure, leaving a crude acidic extract.

\section{Chromatography}

The crude acidic extract was dissolved in $96 \%$ ethanol and strip loaded to a sheet of Whatman No 1 paper. Descending chromatography was used with iso-propanol : ammonia $28 \%$ : water $(10: 1: 1 \mathrm{v} / \mathrm{v})$ as the solvent. The chromatogram was dried in a fume chamber and divided into 10 strips, each corresponding to an $R_{F}$ of 0.1 . Each strip was eluted with $96 \%$ ethanol. The ten eluates were dried at room temperature and taken up in $0.5 \mathrm{ml}$ water containing $0.01 \%$ 'Tween 20 ' for bioassay.

\section{Bioassay}

The bioassay was based on the work of Brian and Hemming (1955). Seeds of dwarf pea 'Meteor' were soaked in running tap water for 6 hours, selected on uniformity, surface-sterilized with $1 \%$ aqueous $\mathrm{HgCl}_{2}$ during $20 \mathrm{~min}$, rinsed in tap water and sown in moist perlite. After five days the seedlings were transferred to $50 \mathrm{ml}$ flasks containing half strength Hoagland solution. Nine days after sowing uniform plants were selected and $0.01 \mathrm{ml}$ of the solution to be assayed was applied next to the growing apex of each of ten replicates. Seven days after this treatment the length of the plant from the first trifoliate leaf to the apex was measured to the nearest millimeter. A standard curve was made using gibberellic acid $\left(\mathrm{GA}_{\mathbf{3}}\right)$. The significance 
of responses to test solutions was calculated at a probability of at least 0.05 . Using the standard curve for $\mathrm{GA}_{3}$ these responses were expressed as $\mathrm{GA}_{3}$ equivalents.

The bioassay with pea plants was carried out at $27^{\circ} \mathrm{C}$ and $80 \%$ relative humidity. Plants were illuminated, 16 hours per day, by fluorescent lamps (Philips TL 65W/29) and incandescent lamps (Philips, $25 \mathrm{~W}$ ), giving a total shortwave irradiation of $21.10^{3}$ and $7.10^{3} \mathrm{erg} \cdot \mathrm{cm}^{-2} \cdot \mathrm{sec}^{-1}$, respectively.

\section{CCC in plant extracts}

Methanol extracts of frozen plant material were concentrated to a known volume and spotted on Whatman No 1 paper. Also spotted on this paper were CCC and choline chloride. Descending chromatography was used with $n$-butanol:acetic acid: water $(4: 1: 1.8 \mathrm{v} / \mathrm{v})$ as the solvent (Zeevaart, 1966). After drying the chromatograms were sprayed with modified Dragendorff reagent (Thies and Reuther, 1954) and the presence of $\mathrm{CCC}$ detected by visual comparison with the standards.

\section{Results}

The morphological changes induced by $\mathrm{CCC}$, like darker green leaves and shorter internodes, were similar to those described earlier by Tognoni et al. (1967). The growth rates of CCC-treated and control plants are represented in Fig. 1, which shows that a single application of $\mathrm{CCC}$ reduces the growth rate of the plants until about 22 days after application. From this time on the growth rate of the treated plants

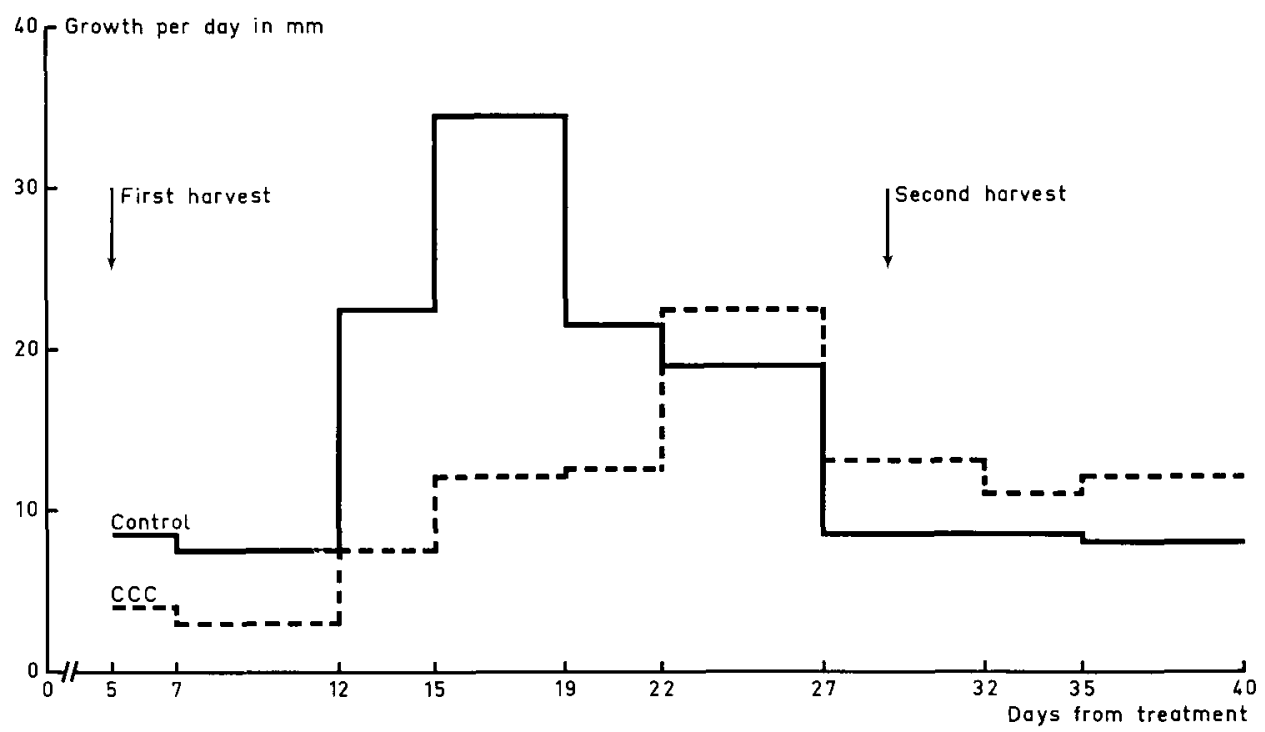

Fig. 1 Growth rates of control and CCC-treated plants, from day 5 until day 40 from treatment. Growth per day is presented as average over time period between data as indicated on the abscissa. Date of sowing $19 / 4 / 68$; treatment on $9 / 5 / 68$. 
is higher compared with the control plants. From the compilation of the measurements of the lengths of the internodes it appeared that after day 22 the increased growth rate of treated plants resulted from accelerated growth of the top internodes. Therefore, this part of the plants was chosen as the second harvest.

The plant material was harvested on the data indicated in Fig. 1. The first harvest consisted of $160 \mathrm{~g} \mathrm{CCC}$-treated and $110 \mathrm{~g}$ control material (fresh weight). For the second harvest these values were both $64 \mathrm{~g}$. The results of paper chromatograms of plant extracts assayed on dwarf pea are given in Fig. 2, which shows that in all extracts one major peak of activity was detected at $R_{F} \quad 0.5-0.7$ (Fraction III). Minor peaks were found at $\mathbf{R}_{F} \quad 0.0-0.1$, which includes the zone of origin (Fraction $\mathbf{I}$ ), $\mathrm{R}_{\mathrm{F}}$ 0.2-0.3 (Fraction II) and $\mathrm{R}_{\mathrm{F}} 0.8-1.0$ (Fraction IV).

Fraction III was found in CCC-treated and in control plants. Fractions I and II appear in CCC-treated plants of the first harvest and increase in treated plants of the second harvest. Fraction IV appears in CCC-treated plants of the first harvest and decreases in CCC-treated plants of the second harvest.

The total amounts of gibberellin-like substances in the extracts were:

\begin{tabular}{lccccc} 
& \multicolumn{2}{c}{ First harvest } & & \multicolumn{2}{c}{ Second harvest } \\
\cline { 2 - 3 } & control & CCC-treated & & control & CCC-treated \\
per gram fresh weight & 0.0007 & 0.0009 & & 0.009 & 0.011
\end{tabular}

Thus extracts from CCC-treated plants harvested during reduced growth or increased growth contain slightly more gibberellin-like substances than controls. In addition, extracts of shoots of older plants contain more gibberellin-like substances than shoots of young plants.

The presence of CCC was detected on chromatograms prepared with extracts of CCCtreated material harvested at day 5 from treatment, but not on chromatograms prepared with material harvested at day 29 from treatment.

\section{Discussion}

A single application of $\mathrm{CCC}$ to the roots of tomato plants reduces plant growth for about three weeks. After this period the growth rate of the top internodes of CCCtreated plants was greater than the comparable parts of control plants. These results are in agreement with previous observations with tomato (Klapwijk, 1966), potato (Dyson, 1965) and strawberry (Guttridge, 1963). Probably the growth promotion of snapdragon by CCC (Halevy and Wittwer, 1965) can also be included as an example. In soil, CCC is broken down in a period of about three weeks (Cathey and Stuart, 1961) as a result of activities of microorganisms (Linser et al., 1965). Conversion of CCC to less effective compounds was observed with barley and chrysanthemum (Schneider, 1967). The present observation that CCC was only detected on chromatograms prepared with extracts of CCC-treated plant material harvested five days after CCC treatment is in agreement with these data. However, CCC applied to Pharbitis nil (Zeevaart, 1966) and Phaseolus vulgaris (Felippe and Dale, 1968) accumulated in seeds and reduced growth of the progeny. In the case of tomato the decrease in growth arrest from the time of $\mathrm{CCC}$ application may have resulted from reduced supply of CCC to the roots, conversion of the compound to less effective substances and 'dilution' as a result of the increase in the volume of the plant. 
The results presented in this paper further show that total gibberellin-like activity of plant extracts was increased at day 5 after application of CCC. Earlier reports have shown that CCC inhibits gibberellin synthesis in plants (Dale and Felippe, 1968; Zeevaart, 1966). However, Reid and Carr (1967) found that CCC increased gibberellinlike activity in extracts from the roots and bleeding sap of Pisum arvense.

Apparently, CCC-inhibited growth of tomato plants is not correlated with a lower level of endogenous gibberellin-like substances. This suggests an unspecific growth inhibition by CCC.

Increased growth of the top internodes of CCC-treated plants, as was observed from day 22 after treatment, may have resulted from the absence of $\mathrm{CCC}$ in these plant parts, and may also be the reflection of a higher level of endogenous gibberellin-like substances. This higher level of gibberellins is explicable when considering the findings that gibberellins are synthesized in roots (Butcher, 1963; Sitton et al., 1967; Skene, 1967) and supplied from the roots to the shoot (Carr et al., 1964), together with the generally made observation that $\mathrm{CCC}$ increases the root system of tomato plants (Morgan and Binchy, 1968; Tognoni et al., 1967; Will, 1966). No explanation can be given for the increase in gibberellin-like substances of the material harvested at day 29 after the time of CCC treatment compared with the material harvested at day 5 from the time of treatment.

In the present study gibberellin-like activity of plant extracts was detected by 'Meteor' pea bioassay. This agrees with the results of Pegg (1966), but contradicts the results of Hill and Selman (1966), who found no activity when tomato plant extracts were tested with this assay.

Fig. 2 shows that the $\mathbf{R}_{F}$ of the major peak of activity coincides with the $\mathbf{R}_{F}$ found
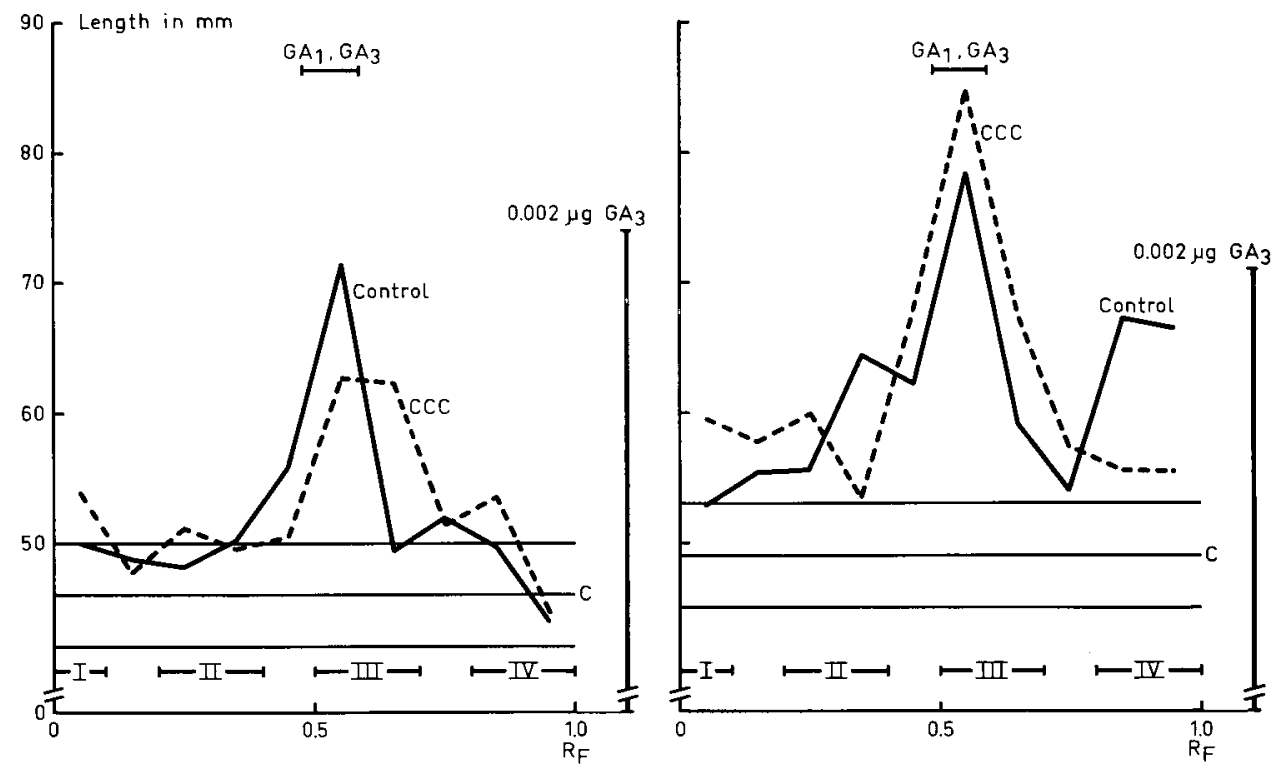

Fig. 2 Dwarf pea bioassay of extracts from control and CCC-treated plant material chromatographed with iso-propanol : ammonia : water $(10: 1: 1)$. Left: first harvest. Right: second harvest. The $5 \%$ fiducial limits are indicated either side of the control line (c). $G A_{1}, G A_{3}=$ position of marker spots. 
for the gibberellins $A_{1}$ and $A_{3}$. Butcher (1963) has found evidence for the presence of gibberellin $A_{1}$ in tomato roots; Bailiss (1968), investigating tomato plant extracts, found a major peak of activity with $R_{\mathrm{F}}$ close to gibberellin $\mathbf{A}_{3}$.

Fig. 2 further shows that $\mathrm{CCC}$ affects the activities found in different zones of the chromatograms, which may reflect qualitative changes of endogenous gibberellins.

\section{References}

Bailiss, K. W., 1968. Gibberellins and the early disease syndrome of aspermy virus in tomato (Lycopersicon esculentum Mill.). Ann. Bot. 32: 543-551.

Brian, P. W. and Hemming, H. G., 1955. The effect of gibberellic acid on shoot growth of pea seedlings. Physiol. Plant. 8: 669-681.

Butcher, D. N., 1963. The presence of gibberellins in excised tomato roots. J. exp. Bot. 14: 272-280.

Carr, D. J., Reid, D. M. and Skene, K. G. M., 1967. The supply of gibberellins from the root to the shoot. Planta 63: 382-392.

Cathey, H. M. and Stuart, N. W., 1961. Comparative plant growth-retarding activity of Amo-1618, phosphon and CCC. Bot. Gaz. 123: 51-57.

Dale, J. E. and Felippe, G. M., 1968. The gibberellin content and early seedling growth of plants of Phaseolus vulgaris treated with the growth retardant CCC. Planta 80: 288-298.

Dyson, P. W., 1965. Effects of gibberellic acid and (2-chloroethyl)-trimethylammonium chloride on potato growth and development. J. Sci. Fd Agric. 16: 542-549.

Felippe, G. M. and Dale, J. E., 1968. Effects of CCC and gibberellic acid on the progeny of treated plants. Planta $80: 344-348$.

Guttridge, C. G., 1963. Physiological investigations on the strawberry. Rep. Scott. hort. Res. Inst. $10: 41-42$.

Halevy, A. H. and Wittwer, S. H., 1965. Growth promotion in the snapdragon by CCC, a growth retardant. Naturwissenschaften 52: 310.

Hill, T. A. and Selman, I. W., 1966. Studies on two gibberellin-like substances in young shoots of tomato (Lycopersicon esculentum Mill.). J. exp. Bot. 17: 534-545.

Klapwijk, D., 1966. Het effect van CCC op de groei van jonge tomateplanten. Meded. Dir. Tuinb. 29: 272-279.

Linser, H., Kühn, H. und Bohring, J., 1965. Der Abbau von Chlorcholinchlorid (CCC) im Boden und sein Nachweis mit geeigneten CCC-Bestimmungsmethoden. Z. PflErnähr. Düng. Bodenk. 108: $57-65$.

Morgan, J. V. and Binchy, A., 1968. Influence of supplementary light, carbon dioxide enrichment and $\mathrm{CCC}$ on the height and dry weight of tomato plants. Irish J. agric. Res. 7: 15-22.

Pegg, G. F., 1966. Changes in levels of naturally occurring gibberellin-like substances during germination of seed of Lycopersicon esculentum Mill.. J. exp. Bot. 17: 214-230.

Reid, D. M. and Carr, D. J,, 1967. Effects of a dwarfing compound, CCC, on the production and export of gibberellin-like substances by root systems. Planta 73: 1-11.

Schneider, E. F., 1967. Conversion of the plant growth retardant (2-chloroethyl) trimethylammonium chloride to choline in shoots of chrysanthemum and barley. Can. J. Biochem. 45: 395-400.

Sitton, D., Richmond, A. and Vaadia, Y., 1967. On the synthesis of gibberellins in roots. Phytochemistry 6: 1101-1105.

Skene, K. G. M., 1967. Gibberellin-like substances in root exudate of Vitis vinifera. Planta 74: 250-262.

Thies, H. und Reuther, F. W., 1954. Ein Reagenz zum Nachweis von Alkaloiden auf Papierchromatogrammen. Naturwissenschaften 41: 230-231.

Tognoni, F., Halevy, A. H. and Wittwer, S. H., 1967. Growth of bean and tomato plants as affected by root absorbed growth substances and atmospheric carbon dioxide. Planta 72: 43-52.

Will, H., 1966. Erste Versuchsergebnisse mit Cycocel zu Tomaten. Gartenbauwissenschaften 31 : 115 123.

Zeevaart, J. A. D., 1966. Reduction of the gibberellin content of Pharbitis seeds by CCC and aftereffects in the progeny. Pl. Physiol. 41: 856-862. 